\title{
111. Triploid Frogs Developed from Fertilized Eggs.
}

\author{
By Tosiziro Kawamura. \\ Zoological Laboratory, Hirosima University, Hirosima. \\ (Comm. by N. YATSU, M.I.A., Dec. 12, 1941.)
}

Regarding the polyploidy in amphibians, we have at present only meager knowledge, because this field of research has a very brief history of a few years. Though many triploid individuals have been found among several species both in the anurans and the urodeles, there are only a few triploids whose sex has been ascertained. Fankhauser ('38, '40, '41) ${ }^{122) 3)}$ reported four triploid newts, Triturus viridescens, a male with normal testes and three females with under-developed ovaries. Griffiths $\left({ }^{\prime} 41\right)^{4)}$ stated that his 15 metamorphosing triploid larvae were all females with rudimentary ovaries. An adult triploid newt, Triton taeniatus, accidentally discovered by Böök ('40) ${ }^{5)}$ among normal diploids was male with the testes containing far fewer spermatozoa than those of diploids. In the anurans Kawamura $\left({ }^{\prime} 39 \mathrm{a}, \mathrm{b},{ }^{\prime} 40\right)^{6) 778)}$ described the structure of the gonads of triploid frogs and tadpoles produced parthenogenetically. Both the testes and ovaries were very abnormal and had a few germ cells or none at all.

In the present paper the sex of triploid frogs produced from fertilized eggs will be described.

Twenty to 40 minutes after fertilization, eggs of Rana nigromaculata were kept at from one to several degrees above $0^{\circ} \mathrm{C}$ for four hours or more. Chromosome numbers of the tadpoles developed from these eggs were counted by the Frankhauser's tail-tip method and many triploids were found among them. It was also found that about onethird of the tadpoles of a control series (No. 7) was triploid. The triploid number of chromosomes was afterwards met with in the mitoses of both spermatogonia and oogonia of many individuals. Each mitotic figure consisted of 15 larger and 24 smaller chromosomes (Fig. 1). More than 70 triploid tadpoles completed metamorphosis and grew normally. Nothing unusual was found both in appearance and in the

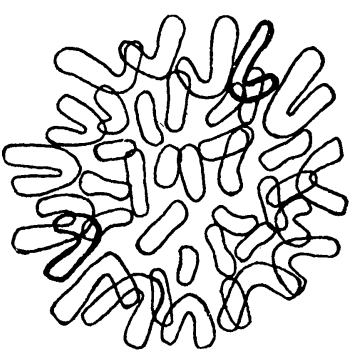

a

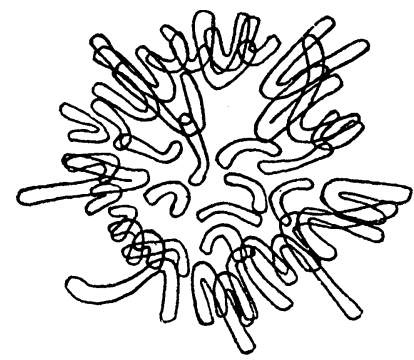

b

Fig. 1. Metaphase chromosomes from triploid germ cells. $\times 2500$.

a. Spermatogonium of triploid male, No. 7. A. 26.

b. Oogonium of triploid female, No. 4. F. 3. 
growth rate as compared with the diploid frogs. Some of them reached maturity and showed the secondary sexual characters such as the thumb pads and vocal sacs. Of 43 triploid frogs 38 were males and the remaining 5 were females as ascertained from the preserved specimens.

In the testes of the adult triploids, spermatozoa were much fewer than in the diploids which were reared under similar conditions, they having been distributed very sparsely in some ampullae, contrary to the compact regular arrangement of spermatozoa of the diploids (Fig. 2).

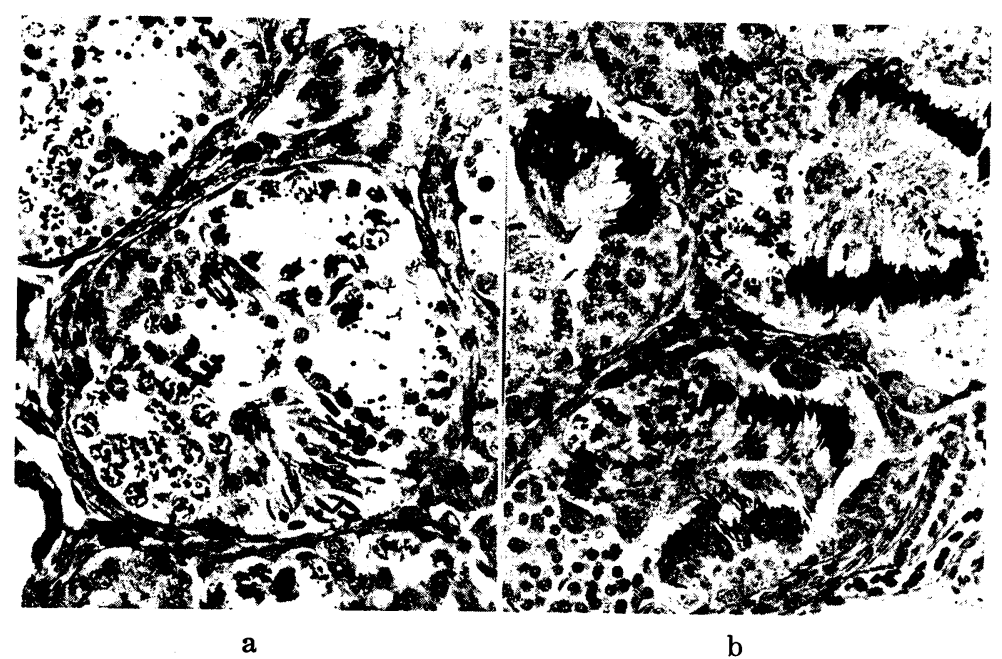

Fig. 2. Sections through testes of triploid male, No. 7. A. 26 (a), and diploid male (b) reared in the laboratory. $\times 210$.

During the first reduction division, mitotic figures contained some univalent, bivalent and trivalent chromosomes. The distribution of chromosomes between the poles in the anaphase were irregular. Most of the primary and secondary spermatocytes degenerated, only a few of them attaining development to spermatids of unequal sizes and eventually to spermatozoa.

In spite of the malformation of the spermatozoa due to the irregularity of meioses, the testes of the triploid frogs were superior in size and differentiation to those of the diploid excepting two triploids with very small and under-developed testes. A comparison between some diploids and triploids reared under nearly the same conditions is as follows. The right testes of seven diploids $29.3-34.6 \mathrm{~mm}$ in body length, were on an average $1.76 \mathrm{~mm}$ long and $0.76 \mathrm{~mm}$ wide, and the left ones $1.87 \mathrm{~mm}$ long and $0.8 \mathrm{~mm}$ wide. In 18 triploids of nearly the same body length, the right testes were $1.68 \mathrm{~mm}$ long and $0.88 \mathrm{~mm}$ wide, and the left ones $1.56 \mathrm{~mm}$ long and $1.01 \mathrm{~mm}$ wide. In the sections of testes of the four frogs a few testis-ova were found, though in the testes of triploids none were present.

The triploid females had small and under-developed ovaries. In the ovary were present the oogonia and young oocytes in the spireme stage, and the growing auxocytes, such as seen in the normal diploid 
ovary, were very scarce. It should be stated that the germ cells in the triploid females were by no means fewer in number than in the normal diploids. In fact oogonial mitoses were few and young oocytes were degenerating. Accordingly the under-development of the ovaries was no other than the suppression of the 'growth of oocytes. The oocytes in the spireme stage seemed eventually to degenerate.

Thirty-five out of the 43 triploid frogs were developed from the fertilized eggs of the same female (No. 7). As to the sex 34 were males and only one female. From control series whose eggs had not been refrigerated 24 diploids were preserved for examination and found that 19 were males and 5 females. From refrigerated eggs of the same female 8 diploid were obtained. They all were males. The male preponderance among the dipldid frogs, together with the fact that their dorsal median stripes were generally curved at the tadpole or young frog stage, make one suspect that the eggs had been overripe. In fact, the mother frog used for this experiment was captured about 50 days after the height of the breeding season, and what is more the eggs were fertilized at $20^{\circ} \mathrm{C}$. It is very probable that the overripeness of the eggs suppresssed or made difficult the formation of the second polar body, and the low temperature intensified this tendency, resulting in the production of more triploids. This also induced to produce more males among the triploids. It may be recalled that in the newt the retained nucleus of the second polar body plays a part in the cause of triploidy as was ascertained by Fankhauser and Griffiths ('39) ${ }^{9)}$ and Griffiths $\left({ }^{\prime} 40\right)^{10)}$. Of the 8 tripiloid frogs developed from the eggs of 3 other females, 4 were males and 4 females. It is supposed that this ratio might have obtained in all the triploids, should the eggs not be overripe.

The fact that the triploid frogs have approximately normal testes or under-developed ovaries is very similar to that observed by Fankhauser $^{3)}$ and Griffiths ${ }^{4)}$ in Triturus and by Böök in Triton. Fankhauser and Griffiths seem to expect from this that the female sex in the newt may be heterogametic. But it seems to me that the cause of underdevelopment of the ovaries in the triploid frogs can not be explained by other than abnormality of trophic conditions common to both sexes, because it is almost certain that the male is heterogametic in the frog. The theory of the male heterogametism was supported by breeding experiments of Witschi and Crew and by my observations on the sex of parthenogenetic frogs $\left({ }^{\prime} 39 \mathrm{a}\right)^{6}$. . It is further strengthened by my experiments performed in 1940, in which 17 out of the 18 diploid parthenogenetic frogs of Rana nigromaculata were female. It is highly probable that the mechanism of sex determination or differentiation is the same both in the newt and in the frog.

The present study was aided by a grant from the Imperial Academy, for which I wish to express my indebtedness. My thanks are also due to Profs. Y. K. Hiraiwa and T. Komai for their continued interest and encouragement. 


\section{Literature.}

1) Fankhauser, G. 1938. Anat. Rec., 72, Suppl., 70.

2) - 1940. Anat. Rec., 77, 227-245.

3) — 1941. Jour. Morph., 68, 161-177.

4) Griffiths, R. B. 1941. Genetics, 26, 69-88.

5) Böök, J. A. 1940. Hereditas, 26, 107-114.

6) Kawamura, T. 1939. Jour. Sci. Hirosima Univ., Ser. B, Div. 1, 7, 39-86.

7) — 1939. Zool. Mag., Tokyo, 51, 629-632.

8) — 1940. Jour. Sci. Hirosima Univ., Ser. B, Div. 1, 8, 117-164.

9) Fankhauser, G. and R. B. Griffiths. 1939. Proc. Nat. Acad. Sci., 25, 233-238.

10) Griffiths, R. B. 1940. Anat. Rec., 76, Suppl., 26-27. 